\title{
Erratum to: Beneficial reward-to-risk action of glucosamine during pathogenesis of osteoarthritis
}

Yeon-Ho Kang ${ }^{1}$, Sujeong Park ${ }^{1}$, Chihyun Ahn ${ }^{1}$, Jinsoo Song ${ }^{1}$, Dongkyun Kim ${ }^{1}$ and Eun-Jung Jin ${ }^{1,2^{*}}$

\section{Erratum to: Eur J Med Res (2015) 20:89 DOI 10.1186/s40001-015-0176-7}

After publication of the original article [1], the authors noticed the Acknowledgements section was incorrect as follows: "This works was supported by National Research Foundation (NRF) of Korea Grant funded by the Korean Governments by the Korea government (MSIP) [2013R1A1A2011999], [NRF-2013R1A2A2A01067194], and [2011-0030130]. The funders had no role in study design, data collection and analysis, decision to publish, or preparation of the manuscript."

The correct version of the Acknowledgements section is included below:

\footnotetext{
Author details

${ }^{1}$ Department of Biological Sciences, College of Natural Sciences, Wonkwang University, Iksan, Chunbuk 570-749, Korea. ${ }^{2}$ Integrated Omics Institute, Wonkwang University, Iksan, Chunbuk 570-749, Korea.
}

\author{
Acknowledgements \\ This paper was sponsored by Joosan Scholarship Foundation of Wonkwang \\ University in 2014.
}

The online version of the original article can be found under doi:10.1186/s40001-015-0176-7.

Received: 21 January 2016 Accepted: 21 January 2016

Published online: 29 January 2016

\section{Reference}

1. Kang YH, Park S, Ahn C, Song J, Kim D, Jin EJ. Beneficial reward-to-risk action of glucosamine during pathogenesis of osteoarthritis. Eur J Med Res. 2015;31(20):89. doi:10.1186/s40001-015-0176-7.

\footnotetext{
*Correspondence: jineunjung@wku.ac.kr

1 Department of Biological Sciences, College of Natural Sciences, Wonkwang University, Iksan, Chunbuk 570-749, Korea
}

Full list of author information is available at the end of the article (c) 2016 Kang et al. This article is distributed under the terms of the Creative Commons Attribution 4.0 International License (http://creativecommons.org/licenses/by/4.0/), which permits unrestricted use, distribution, and reproduction in any medium, provided you give appropriate credit to the original author(s) and the source, provide a link to the Creative Commons license, and indicate if changes were made. The Creative Commons Public Domain Dedication waiver (http://creativecommons.org/ publicdomain/zero/1.0/) applies to the data made available in this article, unless otherwise stated. 